\title{
Hospitalizations for adults with isomerism: a database study from 2005 through 2012
}

\author{
Rohit S. Loomba ${ }^{1 *}$, Matthew Buelow ${ }^{1}$, Saurabh Aggarwal $^{2}$, Karan Njihawan ${ }^{3}$, BS, Rohit R. Arora ${ }^{4}$ and Robert H. Anderson ${ }^{5}$ \\ ${ }^{1}$ Children's Hospital of Wisconsin/Medical College of Wisconsin, USA \\ ${ }^{2}$ Creighton University Medical Center, USA \\ ${ }^{3}$ Rush University Medical Center, USA \\ ${ }^{4}$ Chicago Medical School, USA \\ ${ }^{5}$ Institute of Genetics/Newcastle University, USA
}

\begin{abstract}
Introduction: Isomerism, or heterotaxy, leads to anatomic and functional abnormalities in multiple organ systems. As care improves, an increasing number of patients with isomerism live into adulthood. Complications of isomerism during adulthood are not well understood. This study is aimed to identify trends, frequent causes of admission, and independent predictors of mortality in adult isomerism admissions.

Methods: A cross-sectional study was done using Nationwide Inpatient Sample data from 2005 to 2012. Admissions with isomerism were identified. Characteristics of admissions including demographics, diagnosis data, procedures, length, and cost were compared between those with and without isomerism. Next, trends in the characteristics of only isomerism admissions were compared between the years. Most frequent principle diagnoses were then identified for those with isomerism. Finally, a multivariate regression including all patients was done to identify independent risk factors for mortality.

Results: 59,578,610 admissions were included. Isomerism admissions tended to be younger and have different comorbidities than non-isomerism admissions. Over the years there was minimal change in the frequency of isomerism admissions although average age, length, and cost of admission did increase. Most frequent cause of admission was found to be pneumonia with the remainder of the 10 most frequent also being cardiac or pulmonary. Isomerism was an independent risk factor for mortality along with other factors.
\end{abstract}

Conclusion: Isomerism admissions, although representing a small fraction of total admissions, are longer and costlier than nonisomerism admissions. As the isomerism population lives longer and experiences more complications, admission age, length, and cost are also increasing.

\section{Introduction}

Isomerism, also known as heterotaxy, affects approximately 1 in 10,000 live births and is characterized by the presence of isomerism of the thoracic organs and random arrangement of the abdominal organs [1-5]. Not only can the organs be arranged improperly but they can also otherwise be malformed. More important than the anatomic abnormalities of the organs are the functional abnormalities of the organs that are also found in the setting of isomerism. Anatomic and functional abnormalities have been found in nearly every organ system although the number of affected organ systems is variable among patients [6-14].

Isomerism is best segregated into right and left isomerism based on the morphology of the atrial appendages. Atrial appendage morphology should be used as it is the most constant feature in isomerism, noted particularly in genetic studies involving knockout mice models, and offers the best "syndromic clustering" [15-17]. This allows for inferences to be made on what other anomalies, anatomic and functional, need to be evaluated for or anticipated in the future. Ultimately, this can allow for early detection and intervention. This is particularly important in respect to arrhythmias as well as splenic function $[6,7,18]$.

Those with right isomerism are more likely to have complex congenital malformations of the heart such as atrioventricular septal defect or double outlet right ventricle requiring functionally univentricular palliation. Right isomerism is also associated with absence of a spleen, trilobed lungs bilaterally, and morphologically right bronchuses bilaterally. Left isomerism is associated with less complex congenital malformations of the heart, presence of multiple spleens, bilobed lungs bilaterally, and morphologically left bronchuses bilaterally $[11,12]$. Abnormal splenic function is more likely in the setting of isomerism regardless of splenic anatomy, there is increased prevalence of sinupulmonary symptoms in the setting of isomerism, and there is increased prevalence of arrhythmias in the setting of isomerism as well $[6,7,18]$. Postoperative complications and mortality also differ in those with isomerism when compared to those without isomerism but similar congenital malformations of the heart [19-21].

As cardiac palliation for these patients improves, more of these patients are surviving into adulthood. The overall characteristics of hospital admissions in these patients has not been previously described.

Correspondence to: Rohit S. Loomba, MD, Children's Hospital of Wisconsin/ Medical College of Wisconsin, USA, E-mail: RLoomba@chw.org

Key words: allograft, 5-bromo-2-deoxyuridine (BrdU), differentiation, mesenchymal stem cells, nerve regeneration

Received: July 13, 2016; Accepted: August 02, 2016; Published: August 05, 2016 
This study utilizes 8 years of data from the Nationwide Inpatient Sample to describe the trends in isomerism admissions and identify risk factors associated with mortality.

\section{Methods}

Institutional review board review approval was waived as this study utilizes deidentified data from a national database. Consent was not obtained by the authors for this study as the data was derived from a national database. This cross-sectional study is in compliance with the Helsinki declaration.

\section{Nationwide inpatient sample}

The Nationwide Inpatient Sample, Healthcare Cost Utilization Project (HCUP) by the Agency for Healthcare Research and Quality (AHRQ) is a large database designed to capture data from approximately $20 \%$ of all community hospital admissions in the United States. All patients cared for at these selected hospitals are included in the Nationwide Inpatient Sample. Rehabilitation and long-term acute care hospitals are excluded from this database. Patients from all regions of the United States with a variety of payer types are captured in this database. Data from a total of 44 states is captured. A majority of admissions in this database involve adult patients. The Nationwide Inpatient Sample data uses a self-weighting design to help reduce confidence intervals. Data variance from the Nationwide Inpatient Sample can be self-validated for specific iterations.

\section{Patient identification}

Data regarding hospital admissions was obtained 8 iterations of the Nationwide Inpatient Sample covering the years 2005 through 2012. Patients with isomerism were identified using the International Classification of Diseases, Ninth Revision (ICD-9) code 746.87. Patients with situs inversus were not included in this group as not all situs inversus portends isomerism.

No patients were excluded from this analysis. Unfortunately it is not possible from the Nationwide Inpatient Sample data to determine which admissions represented readmissions within the same year so this could not be accounted for.

\section{Data identification and collection}

Demographic information including, gender, and race were collected for each admission. Admission characteristics such as admission month, length of stay, and cost of stay were collected as well. Information regarding comorbid conditions was also collected. Hyperlipidemia was identified using 272.0, 272.1, 272.2, and 272.3 hypertension using 401.0, 401.1 and 401.9. Overweight or obese patients were identified using 278.00, 278.01, and 278.02 with smokers being identified by 305.1 .

Data of interest in regards to isomerism included cardiac anatomy as well splenic anatomy. The following congenital cardiac malformations commonly associated with isomerism were collected: functionally univentricular hearts using 745.3, double outlet right ventricle using 745.11 , atrioventricular septal defect using 745.60 and 745.69, partial anomalous pulmonary venous connection using 747.42, and total anomalous pulmonary venous connection using 747.41. Splenic abnormality, either absence of a spleen or presence of multiple spleens, was collected using 759.0. It was not possible to distinguish between those with absence of a spleen or multiple spleens due to the ICD-9 coding strategy.

\section{Statistical analysis}

A cross-sectional study was conducted. Continuous variables are reported using mean and standard deviation while categorical variables are reported using absolute frequency and percentages. Continuous variables were analyzed using a student t-test or Mann-Whitney-U test as appropriate with categorical variables being analyzed using chi-square analysis. Baseline characteristics such as age, gender, race, and comorbid conditions were compared between those with and without isomerism. Hospitalization characteristics including length of admission, cost of admission, and number of procedures during the admission were also compared between those with and without isomerism. Next, the number of isomerism admissions was compared by each year.

Only isomerism admissions were then compared throughout the years. Characteristics such as mortality, race, gender, age, length of admission, and cost of admission were compared by year. Finally, the principle diagnosis for all isomerism admissions was identified to determine the most frequent cause of admission. For some patients, isomerism or data regarding congenital malformations of the heart were coded as the principle diagnosis. These were excluded from this analysis.

Finally, a multivariate logistic regression was done to determine independent predictors of death. All patients were included in this analysis. The dependent variable was mortality. The following independent variables were entered into the regression: age, year of admissions, gender, race, current smoking status, isomerism, diabetes mellitus, hyperlipidemia, myocardial infarction, heart failure double outlet right ventricle, functionally univentricular heart, partial anomalous venous connection, total anomalous venous connection, obesity arrhythmia, and splenic anomaly.

All statistical analysis was done utilizing SPSS Version 20.0 (Chicago, IL). A p-vale of less than 0.05 was considered statistically significant.

\section{Results}

A total of 59,578,610 admissions were included in the analysis. Of these, 6,587 (0.011\%) were isomerism admissions. Characteristics of admissions with and without isomerism did have significant differences. Those with isomerism tended to be younger and male $(\mathrm{p}<0.0001)$. Average age of isomerism admissions was 27.49 years compared to 50.97 years for non-isomerism admissions. Current smoking (odds ratio $0.395,95 \%$ confidence interval 0.352 to 0.444 ), hyperlipidemia (odds ratio $0.413,95 \%$ confidence interval 0.351 to 0.486 ), type 2 diabetes mellitus (odds ratio 0.424 , 95\% confidence interval 0.390 to 0.461 ), and overweight/obesity (odds ratio $0.554,95 \%$ confidence interval 0.491 to 0.624 ) were less likely with isomerism. Congenital malformations of the heart, particularly double outlet right ventricle (odds ratio $1,185.735,95 \%$ confidence interval $1,081.204$ to $1,300.375$ ), functionally univentricular heart (odds ratio $1,810.882$, $95 \%$ confidence interval $1,639.191$ to $2,000.556$ ), partial anomalous pulmonary venous connection (odds ratio 318.804, 95\% confidence interval 234.988 to 432.516 ), total anomalous pulmonary venous connection (odds ratio $1,263.049,1,091.649$ to $1,461.361$ ), tetralogy of Fallot (odds ratio $58.885,95 \%$ confidence interval 46.864 to 73.989 ) were more prevalent with isomerism. Coronary artery anomaly (odds ratio $34.550,95 \%$ confidence interval 25.401 to 46.995 ), atrial septal defect (odds ratio $41.608,95 \%$ confidence interval 38.662 to 44.778 ), ventricular septal defect (odds ratio 93.866, 95\% confidence interval 
86.317 to 102.076 ), and coarctation of the aorta (odds ratio 110.808 , $95 \%$ confidence interval 92.801 to 132.308 ) were also more prevalent with isomerism. Anatomic splenic anomalies, pancreatic anomalies (odds ratio $19.140,95 \%$ confidence interval 9.561 to 38.317 ), and other extracardiac anomalies were also more prevalent with isomerism (Table 1).

Isomerism admissions tended to be longer $(8.95 \pm 18.37$ versus $4.74 \pm 6.94, \mathrm{p}<0.0001)$ and costlier $(\$ 84,333.74 \pm 192,517.52$ versus
$\$ 31,142.58 \pm 54,885.56, \mathrm{p}<0.0001)$ when compared to non-isomerism admissions. The number of procedures during admissions was also greater for isomerism admissions $(2.88 \pm 3.73$ versus $1.64 \pm 2.09, \mathrm{p}<$ $0.0001)$. Mortality was also more likely with isomerism admissions (odds ratio 2.154, 95\% confidence interval 1.914 to 2.425) (Table 1).

The percentage of isomerism admissions was statistically significant between the included years, although the actual number of admissions is unlikely to be clinically significant. The greatest percentage of

Table 1. Characteristics of isomerism and non-isomerism admissions.

\begin{tabular}{|c|c|c|c|c|}
\hline & No isomerism $(\mathrm{n}=\mathbf{5 9 , 5 7 2 , 0 2 3 )}$ & $\begin{array}{l}\text { Isomerism } \\
(\mathrm{n}=\mathbf{6 , 5 8 7})\end{array}$ & $\begin{array}{|lll|}\begin{array}{l}\text { Odds ratio } \\
\text { interval })\end{array} & (95 \% & \text { confidence } \\
\end{array}$ & p-value \\
\hline Age at admission (years) & $50.97 \pm 26.08$ & $27.49 \pm 30.97$ & -- & $<0.0001$ \\
\hline Female & $34,942,669(58.8)$ & $3,133(47.6)$ & $0.637(0.607$ to 0.668$)$ & $<0.0001$ \\
\hline Current smoker & $6,353,192(10.7)$ & $297(4.5)$ & $0.396(0.352$ to 0.444$)$ & $<0.0001$ \\
\hline Hyperlipidemia & $3,138,916(5.3)$ & $148(2.2)$ & $0.413(0.351$ to 0.486$)$ & $<0.0001$ \\
\hline Diabetes mellitus & $11,655,371(19.6)$ & $616(9.3)$ & $0.424(0.390$ to 0.461$)$ & $<0.0001$ \\
\hline Myocardial infarction & $551,140(1.0)$ & $40(0.6)$ & $0.611(0.448$ to 0.834$)$ & 0.002 \\
\hline Heart failure & $6,898,017(11.6)$ & $1,003(15.2)$ & $1.372(1.283$ to 1.467$)$ & $<0.0001$ \\
\hline Overweight or obese & $4,392,163(7.4)$ & $278(4.2)$ & $0.554(0.491$ to 0.624$)$ & $<0.0001$ \\
\hline Hypertension & $19,474,018(32.7)$ & $1,212(18.4)$ & $0.464(0.436$ to 0.494$)$ & $<0.0001$ \\
\hline Acute kidney injury & $3,823,072(6.4)$ & $331(5.0)$ & $0.772(0.691$ to 0.862$)$ & $<0.0001$ \\
\hline Chronic kidney disease & $4,857,367(8.1)$ & $311(4.7)$ & $0.558(0.498$ to 0.626$)$ & $<0.0001$ \\
\hline Arrhythmia & $5,867,131(9.8)$ & $698(10.6)$ & 1.085 (1.003 to 1.174$)$ & 0.041 \\
\hline Atrioventricular block & $315,454(0.5)$ & $75(1.1)$ & 2.164 (1.723 to 2.717$)$ & $<0.0001$ \\
\hline $\begin{array}{l}\text { Race } \\
\text { White } \\
\text { Black } \\
\text { Hispanic } \\
\text { Asian or Pacific Islander } \\
\text { Native American } \\
\text { Other }\end{array}$ & $\begin{array}{l}32,792,566(67.1) \\
6,962,641(14.2) \\
5,915,267(12.1) \\
1,219,176(2.5) \\
337,813(0.7) \\
1,644,067(3.4)\end{array}$ & $\begin{array}{l}2,937(53.6) \\
719(13.1) \\
1,291(23.6) \\
201(3.7) \\
49(0.9) \\
279(5.1)\end{array}$ & -- & $<0.0001$ \\
\hline Atrial septal defect & $201,777(0.3)$ & $816(12.4)$ & 41.608 (38.662 to 44.778$)$ & $<0.0001$ \\
\hline Ventricular septal defect & $64,357(0.1)$ & $607(9.2)$ & $93.866(86.317$ to 102.076$)$ & $<0.0001$ \\
\hline Coarctation of the aorta & $10,484(0.1)$ & $126(1.9)$ & $110.808(92.801$ to 132.308$)$ & $<0.0001$ \\
\hline Tetralogy of Fallot & $11,651(0.1)$ & $75(1.1)$ & 58.885 (46.864 to 73.989$)$ & $<0.0001$ \\
\hline Common ventricle & $2,644(0.1)$ & $490(7.4)$ & $1,810.882(1,639.191$ to $2,000.556)$ & $<0.0001$ \\
\hline \multicolumn{5}{|l|}{ Hypoplastic left heart syndrome } \\
\hline Double outlet right ventricle & $4,541(0.1)$ & $546(8.3)$ & $1,185.736(1,081.204$ to $1,300.375)$ & $<0.0001$ \\
\hline Atrioventricular septal defect & $7,614(0.1)$ & $475(7.2)$ & & \\
\hline Transposition of the great arteries & $3,968(0.1)$ & $265(4.0)$ & 629.346 (554.411 to 714.408$)$ & $<0.0001$ \\
\hline Congenitally corrected transposition of the great arteries & $1,389(0.1)$ & $120(1.8)$ & $795.920(659.462$ to 960.613$)$ & $<0.0001$ \\
\hline Pulmonary atresia & $2,583(0.1)$ & $184(2.8)$ & $662.815(569.61$ to 771.268$)$ & $<0.0001$ \\
\hline Tricuspid atresia & $3,419(0.1)$ & $121(1.8)$ & $326.083(271.570$ to 391.540$)$ & $<0.0001$ \\
\hline Ebstein's anomaly & $2,571(0.1)$ & $17(0.3)$ & $59.961(37.194$ to 96.664$)$ & $<0.0001$ \\
\hline Partial anomalous pulmonary venous connection & $1,228(0.1)$ & $43(0.7)$ & 318.804 (234.988 to 432.516$)$ & $<0.0001$ \\
\hline Total anomalous pulmonary venous connection & $1,561(0.1)$ & $211(3.2)$ & $1,263.049(1,091.649$ to $1,461.361)$ & $<0.0001$ \\
\hline Coronary artery anomaly & $10,799(0.1)$ & $41(0.6)$ & $34.550(25.401$ to 46.995$)$ & $<0.0001$ \\
\hline Splenic anomaly & $4,768(0.1)$ & $253(3.8)$ & 499.080 (438.756 to 567.699$)$ & $<0.0001$ \\
\hline Pancreatic anomaly & $3,785(0.1)$ & $8(0.1)$ & $19.140(9.561$ to 38.317$)$ & $<0.001$ \\
\hline Intestinal malrotation & $8,532(0.1)$ & $124(1.9)$ & 133.961 (112.011 to 160.212$)$ & $<0.0001$ \\
\hline Volvulus & $32,190(0.1)$ & $14(0.2)$ & $3.940(2.332$ to 6.657$)$ & $<0.0001$ \\
\hline Atresia or stenosis, small intestine & $4,792(0.1)$ & $14(0.2)$ & $26.480(15.662$ to 44.770$)$ & $<0.0001$ \\
\hline Atresia or stenosis, large intestine & $7,826(0.1)$ & $6,590(0.9)$ & $68.799(53.192$ to 88.984$)$ & $<0.0001$ \\
\hline Biliary atresia & $2,676(0.1)$ & $10(0.2)$ & 33.851 (18.184 to 63.016$)$ & $<0.0001$ \\
\hline Congenital cysts of the liver & $3,596(0.1)$ & $1(0.1)$ & $2.516(0.354$ to 17.866$)$ & 0.339 \\
\hline Congenital hydrocephalus & $21,086(0.1)$ & $43(0.7)$ & $18.560(13.747$ to 25.058$)$ & $<0.0001$ \\
\hline Length of hospitalization (days) & $4.74 \pm 6.94$ & $8.95 \pm 18.37$ & -- & $<0.0001$ \\
\hline Cost of hospitalization (US dollars) & $31,142.58 \pm 54,885.56$ & $84,333.74 \pm 192,517.52$ & -- & $<0.0001$ \\
\hline Number of procedures during hospitalization & $1.64 \pm 2.09$ & $2.88 \pm 3.73$ & -- & $<0.0001$ \\
\hline Mortality & $1,233,819(2.1)$ & $287(4.4)$ & $2.154(1.914$ to 2.425$)$ & $<0.0001$ \\
\hline
\end{tabular}

Characteristics of hospitalizations for those with and without isomerism. 
isomerism admissions was $0.014 \%$ of all admissions in 2005 with the lowest percentage of isomerism admissions being $0.009 \%$ of all admissions in both 2006 and 2007 ( $<<0.0001)$ (Table 2).

When characteristics of only isomerism admissions were compared by year, significant differences were noted as well. Age of admission, length of hospitalization, and cost of hospitalization all increased over the study period $(\mathrm{p}<0.0001)$. Mortality did not demonstrate a significant change over the years $(\mathrm{p}=0.052)$ (Table 3$)$.

The 10 most frequent principle diagnoses for isomerism admissions are listed in Table 4. The most frequent principle diagnosis was pneumonia which was present in 327 (5.0) admissions, with unspecified heart failure being the second most common being present in 221 (3.4) admissions, and the third most common being atrial fibrillation in 102 (1.5) admissions.

Multivariate logistic regression identified the following independent risk factors associated with mortality: age (odds ratio 1.036, 95\% confidence interval 1.035 to 1.036), male gender (odds ratio $1.254,95 \%$ confidence interval 1.246 to 1.262 ), splenic anomaly (odds ratio 1.759, 95\% confidence interval 1.072 to 2.887 ), arrhythmia (odds ratio $1.418,95 \%$ confidence interval 1.400 to 1.437 ), myocardial infarction (odds ratio $4.985,95 \%$ confidence interval 4.877 to 5.094 ), heart failure (odds ratio $1.456,95 \%$ confidence interval 1.438 to 1.475 ), double outlet right ventricle (odds ratio $13.756,95 \%$ confidence interval 9.856 to 19.199), functionally univentricular heart (odds ratio 3.200,

Table 2. The number of isomerism hospitalization and the percentage of total admissions by year.

\begin{tabular}{|l|c|}
\hline & Isomerism hospitalizations \\
\hline $\mathbf{2 0 0 5}(n=7,511,596)$ & $1,019(0.014)$ \\
\hline $\mathbf{2 0 0 6}(n=7,588,555)$ & $656(0.009)$ \\
\hline $\mathbf{2 0 0 7}(n=7,539,725)$ & $706(0.009)$ \\
\hline $\mathbf{2 0 0 8}(n=7,686,151)$ & $841(0.011)$ \\
\hline $\mathbf{2 0 0 9}(n=7,371,814)$ & $778(0.011)$ \\
\hline $\mathbf{2 0 1 0}(n=7,398,382)$ & $878(0.012)$ \\
\hline $\mathbf{2 0 1 1}(n=7,605,529)$ & $856(0.011)$ \\
\hline $\mathbf{2 0 1 2}(n=6,906,253)$ & $856(0.012)$ \\
\hline
\end{tabular}

Table 3. Characteristics of isomerism admission compared by year.

\begin{tabular}{|l|c|c|c|c|c|c|c|c|}
\hline & $\mathbf{2 0 0 5}$ & $\mathbf{2 0 0 6}$ & $\mathbf{2 0 0 7}$ & $\mathbf{2 0 0 8}$ & $\mathbf{2 0 0 9}$ & $\mathbf{2 0 1 0}$ & $\mathbf{2 0 1 1}$ \\
\hline $\begin{array}{l}\text { Age at admission } \\
\text { (years) }\end{array}$ & 20.22 & 26.69 & 28.82 & 31.12 & 30.53 & 28.43 & 30.33 & 25.49 \\
\hline Female & $452(44.4)$ & $329(50.2)$ & $349(49.5)$ & $432(51.4)$ & $350(45.0)$ & $427(48.6)$ & $415(48.5)$ & $379(44.3)$ \\
\hline $\begin{array}{l}\text { Length of } \\
\text { hospitalization }\end{array}$ & 8.00 & 7.64 & 7.51 & 8.15 & 8.01 & 10.16 & 10.56 \\
\hline $\begin{array}{l}\text { Cost of hospitalization } \\
\text { (US dollars) }\end{array}$ & $58,946.87$ & $55,127.63$ & $71,646.28$ & $70,327.45$ & $77,267.80$ & $89,220.47$ & $113,877.40$ & $134,151.61$ \\
\hline Mortality & $37(3.6)$ & $18(2.7)$ & $33(4.7)$ & $37(4.4)$ & $37(4.4)$ & $30(3.4)$ & 50.0001 \\
\hline
\end{tabular}

Table 4. Most frequent principle diagnoses for isomerism admissions.

\begin{tabular}{|c|c|c|}
\hline Rank & Diagnosis \\
\hline $\mathbf{1}$ & Pneumonia & $327(5.0)$ \\
\hline $\mathbf{2}$ & Heart failure, unspecified \\
\hline $\mathbf{3}$ & Atrial fibrillation & $221(3.4)$ \\
\hline $\mathbf{4}$ & Chest pain, other & $102(1.5)$ \\
\hline $\mathbf{6}$ & Coronary atherosclerosis \\
\hline $\mathbf{7}$ & Cardiac arrhythmia, other \\
\hline $\mathbf{8}$ & Acute respiratory failure & $99(1.5)$ \\
\hline $\mathbf{9}$ & Acute on chronic systolic heart failure \\
\hline $\mathbf{1 0}$ & Obstructive chronic bronchitis, acute exacerbation & $77(1.2)$ \\
\hline & Acute upper respiratory infection & $76(1.2)$ \\
\hline
\end{tabular}

95\% confidence interval 1.894 to 5.407), partial anomalous pulmonary venous connection (odds ratio $4.694,95 \%$ confidence interval 1.879 to 11.727), total anomalous pulmonary venous connection (odds ratio $7.590,95 \%$ confidence interval 4.371 to 13.181 ), and isomerism (odds ratio $1.776,95 \%$ confidence interval 1.204 to 2.619 ) (Table 5).

\section{Discussion}

Isomerism is a complex clinical entity that can lead to anatomic and functional abnormalities in nearly any organ system. Congenital malformations of the heart are common and are often complex and require multiple cardiac surgeries. Improvements in the care for these patients has led to an increased number surviving into adulthood. This study is the first large study to characterize hospital admissions of adults with isomerism. This study demonstrates that the percentage of total admissions that are isomerism admissions has seemed to remain constant over the study period with about 1 in 10,000 admissions being isomerism admissions. Over the study period, age at admission, length of hospitalization, and cost of hospitalization all increased for isomerism admissions. Multivariate analysis found that isomerism is an independent risk factor for mortality.

The 10 most common principle diagnoses for isomerism admissions were all either cardiac or pulmonary in nature. The 3 most common were pneumonia, heart failure, and atrial fibrillation. Those with isomerism will often have splenic dysfunction even if they have a normally located, normal appearing spleen [18]. This puts them at increased risk for infection, particularly from encapsulated organisms $[22,23]$. The risk of bacteremia from such splenic dysfunction appears to be greatest in the first 3 years of life [23]. This in fact has been noted in the isomerism and sickle cell population, both of whom can have splenic dysfunction. Since splenic function and specific splenic anatomy could not be delineated in great detail for each patient in the database it was not possible to determine the cause of pneumonia in this particular population of patients.

The prevalence of heart failure admissions in adults with isomerism can easily be understood as these patients will often have complex congenital malformations of the heart $[11,17,24-26]$. Most commonly these consist of atrioventricular septal defect and/or double outlet 
Table 5. Independent risk factors for mortality identified by multivariate regression analysis.

\begin{tabular}{|l|c|c|}
\hline \multicolumn{1}{|c|}{ Odds ratio (95\% confidence interval) } \\
\hline Age & $1.036(1.035$ to 1.036$)$ \\
\hline Male & $1.254(1.246$ to 1.262$)$ \\
\hline Splenic anomaly & $1.759(1.072$ to 2.887$)$ \\
\hline Arrhythmia & $1.418(1.400$ to 1.437$)$ \\
\hline Myocardial infarction & $4.985(4.877$ to 5.094$)$ & $<0.0001$ \\
\hline Heart failure & $1.456(1.438$ to 1.475$)$ & $<0.0001$ \\
\hline Double outlet right ventricle & $13.756(9.856$ to 19.199$)$ \\
\hline Functionally univentricular & $3.200(1.894$ to 5.407$)$ \\
\hline Partial anomalous pulmonary venous connection & $4.694(1.879$ to 11.727$)$ \\
\hline Total anomalous pulmonary venous connection & $7.590(4.371$ to 13.181$)$ & $<0.0001$ \\
\hline Isomerism & $1.540(1.032$ to 2.300$)$ & $<0.0001$ \\
\hline
\end{tabular}

right ventricle, some of these patients who will require functionally univentricular palliation. Such repair requires staged palliation that eventually redirects all systemic venous return directly into the lungs and leaves the functional single ventricle to handle output to the systemic circulation. Often times this will be a morphologic right ventricle which over time begins to fail against systemic resistance.

The increased prevalence of arrhythmias and related admissions is also well described in children and adults with isomerism and is often due to abnormalities in how the conduction system has formed $[6,7]$. For instance, dual sinoatrial nodes may be present in the setting of right isomerism while there may be absence in the setting of left isomerism. Dual atrioventricular nodes are also often present in isomerism with variability in the connections between the atrioventricular nodes and the ventricular conduction system [27].

This study also demonstrates that isomerism admissions are now increasing in age, length, and cost. This can be explained by the improved care for these patients which is now allowing them to longer into adulthood. This it is not surprising that the average age of isomerism admissions is increasing. As these patients live longer, however, more complications from their underlying disease as well as surgical palliations is becoming manifest, likely contributing to the increase in length and cost of admissions. These issues include failing Fontan physiology, plastic bronchitis, protein losing enteropathy, pulmonary hypertension, arrhythmias, and heart failure [28-30].

Caring for adults with isomerism requires thorough understanding of the possible manifestations of isomerism, both anatomic and functional. It is vital to obtain complete knowledge of surgical palliations and comorbidities that these patients already have as this can greatly impact the care they receive. Treatment efficacy and adverse effects may have different implications in these patients. Understanding the trends of a contemporary cohort of these patients allows for anticipation of what may be expected for these patients but can also help guide patient education so that patients can have increased vigilance for signs and symptoms of developing conditions and receive earlier care that may prevent inpatient admission. Reevaluation of trends throughout the years is also important as it allows for assessment of how care has evolved and whether improvements have been made in decreasing the morbidity and mortality associated with isomerism. Thus, this analysis provides a comparative point for future analysis.

This analysis benefits from a large sample size which allows for the analysis of even rare conditions, such as is the case with isomerism. Additionally, enough data is present to be able to collect data on several coexisting conditions and thus account for these in multivariate models.
This study is not without its limitations, however. Firstly, we were unable to segregate isomerism into the right or left. Additionally, coding for congenital cardiac malformations is not ideal to help extract precise information about the cardiac anatomy that would be needed to assign an isomerism subtype using surrogate markers. Other anatomic findings to help segregate into right and left isomerism, such as splenic anatomy, are also not precise as both absence of a spleen and presence of multiple spleens were coded with a single code. Properly capturing the arrangement of the abdominal organs was not possible for similar reasons. Also, not all ICD-9 codes have been validated over the years, particularly those used to code for congenital cardiac malformations. Congenital cardiac malformations may be undercoded once these patients reach adulthood and thus the numbers provided here may be underestimates of the true prevalence.

\section{Conclusion}

Isomerism admissions are associated with increased length, cost, and mortality when compared to non-isomerism admissions. The frequency of such admissions has not changed over the last decade although the admission are occurring at older ages and are becoming longer and costlier. Isomerism is an independent risk factor for mortality.

\section{References}

1. Evans WN, Acherman RJ, Restrepo H (2015) Heterotaxy in southern Nevada: prenatal detection and epidemiology. Pediatr Cardiol 36: 930-934. [Crossref]

2. Lin AE, Krikov S, Riehle-Colarusso T, Frias JL, Belmont J, et al. (2014) Laterality defects in the national birth defects prevention study (1998-2007): birth prevalence and descriptive epidemiology. Am J Med Genet A. 164A: 2581-2591. [Crossref]

3. Lopez KN, Marengo LK, Canfield MA, Belmont JW, Dickerson HA (2015) Racia disparities in heterotaxy syndrome. Birth Defects Res A Clin Mol Teratol 103: 941-950. [Crossref]

4. Jacobs JP, Anderson RH, Weinberg PM, Walters HL, Tchervenkov CI, et al (2007) The nomenclature, definition and classification of cardiac structures in the setting of heterotaxy. Cardiol Young 17 Suppl 2: 1-28. [Crossref]

5. Loomba RS, H avacek AM, Spicer DE, Anderson RH (2015) Isomerism or heterotaxy: which term leads to better understanding? Cardiol Young 25: 1037-1043. [Crossref]

6. Loomba RS, Aggarwal S, Gupta N, Buelow M, Alla V, et al. (2016) Arrhythmias in Adult Congenital Patients With Bodily Isomerism. Pediatr Cardiol 37: 330-337. [Crossref]

7. Loomba RS, Willes RJ, Kovach JR, Anderson RH (2016) Chronic Arrhythmias in the Setting of Heterotaxy: Differences between Right and Left Isomerism. Congenit Heart Dis 11: 7-18. [Crossref]

8. Loomba RS, Pelech AN, Shah PH, Anderson RH (2016) Determining bronchia morphology for the purposes of segregating so-called heterotaxy. Cardiol Young 26: 725-737. [Crossref]

9. Loomba RS, Chandrasekar S, Shah PH, Sanan P (2011) The developing role of fetal magnetic resonance imaging in the diagnosis of congenital cardiac anomalies: A 
systematic review. Ann Pediatr Cardiol 4: 172-176. [Crossref]

10. Loomba R, Shah PH, Anderson RH (2015) Fetal Magnetic Resonance Imaging of Malformations Associated with Heterotaxy. Cureus 7: e269. [Crossref]

11. Loomba RS, Ahmed MM, Spicer DE, Backer CL, Anderson RH (2016) Manifestations of bodily isomerism. Cardiovasc Pathol 25: 173-180. [Crossref]

12. Loomba R, Shah PH, Anderson RH, Arora Y (2016) Radiologic Considerations in Heterotaxy: The Need for Detailed Anatomic Evaluation. Cureus 8: e470. [Crossref]

13. Loomba R1 (2015) Thrombocytosis in the Setting of Isomerism and a Functionally Univentricular Heart. Cureus 7: e383. [Crossref]

14. Kothari SS1 (2014) Non-cardiac issues in patients with heterotaxy syndrome. Ann Pediatr Cardiol 7: 187-192. [Crossref]

15. Van Praagh R, Van Praagh S (1990) Atrial isomerism in the heterotaxy syndromes with asplenia, or polysplenia, or normally formed spleen: an erroneous concept. $A m J$ Cardiol 66: 1504-1506. [Crossref]

16. van Praagh R, David I, Wright GB, van Praagh S (1980) Large RV plus small LV is not single RV. Circulation 61: 1057-1059. [Crossref]

17. Uemura H, Ho SY, Devine WA, Anderson RH (1995) Analysis of visceral heterotaxy according to splenic status, appendage morphology, or both. Am J Cardiol 76: 846-849. [Crossref]

18. Nagel BH, Williams H, Stewart L, Paul J, Stümper O (2005) Splenic state in surviving patients with visceral heterotaxy. Cardiol Young 15: 469-473. [Crossref]

19. Loomba RS (2016) Arterial desaturation due to pulmonary arteriovenous malformations after the Kawashima Operation. Ann Pediatr Cardiol 9: 35-38. [Crossref]

20. Loomba $\mathrm{R}$ (2015) Comment on pulmonary hypertension in a patient with congenital heart defects and heterotaxy syndrome. Ochsner Journal 15: 401. [Crossref]

21. Loomba RS, Nijhawan K, Anderson R (2016) Impact of Era, Type of Isomerism, and Ventricular Morphology on Survival in Heterotaxy: Implications for Therapeutic Management. World J Pediatr Congenit Heart Surg 7: 54-62. [Crossref]

22. Waldman JD, Rosenthal A, Smith AL, Shurin S, Nadas AS (1977) Sepsis and congenital asplenia. J Pediatr 90: 555-559. [Crossref]

23. Prendiville TW, Barton LL, Thompson WR, Fink DL, Holmes KW (2010) Heterotaxy syndrome: defining contemporary disease trends. Pediatr Cardiol 31: 1052-1058. [Crossref]

24. Uemura H, Ho SY, Devine WA, Kilpatrick LL, Anderson RH (1995) Atrial appendages and venoatrial connections in hearts from patients with visceral heterotaxy. Ann Thorac Surg 60: 561-569. [Crossref]

25. Uemura H, Ho SY, Anderson RH, Devine WA, Smith A, et al. (1995) The surgical anatomy of coronary venous return in hearts with isomeric atrial appendages. $J$ Thorac Cardiovasc Surg 110: 436-444. [Crossref]

26. Uemura H, Ho SY, Anderson RH, Yagihara T (1999) Ventricular morphology and coronary arterial anatomy in hearts with isometric atrial appendages. Ann Thorac Surg 67: 1403-1411. [Crossref]

27. Smith A, Ho SY, Anderson RH, Connell MG, Arnold R, et al. (2006) The diverse cardiac morphology seen in hearts with isomerism of the atrial appendages with reference to the disposition of the specialised conduction system. Cardiol Young 16: 437-454. [Crossref]

28. Gentles TL, Mayer JE, Jr., Gauvreau K, Newburger JW, Lock JE, et al. (1997) Fontan operation in five hundred consecutive patients: factors influencing early and late outcome. J Thorac Cardiovasc Surg 114: 376-391. [Crossref]

29. Hsu DT1 (2015) The Fontan operation: the long-term outlook. Curr Opin Pediatr 27: 569-575. [Crossref]

30. McRae ME1 (2013) Long-term issues after the Fontan procedure. AACN Adv Crit Care 24: 264-282. [Crossref]

Copyright: C2016 Loomba RS. This is an open-access article distributed under the terms of the Creative Commons Attribution License, which permits unrestricted use, distribution, and reproduction in any medium, provided the original author and source are credited. 